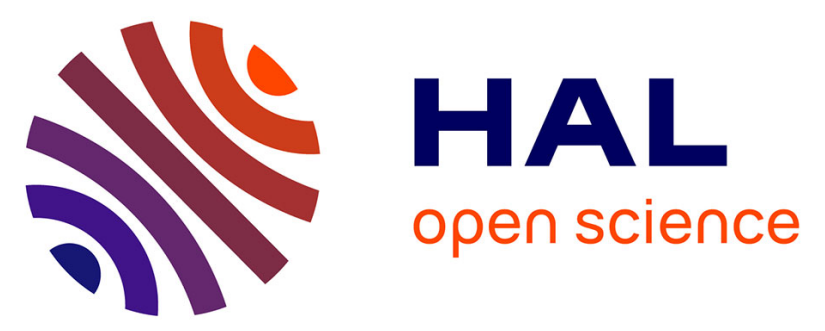

\title{
Process and Data-Oriented Approach for Bundling Corporate Reporting Duties to Public Authorities - A Case Study on the Example of Waste Management Reporting
}

\author{
Armin Sharafi, Petra Wolf, Helmut Krcmar
}

\section{To cite this version:}

Armin Sharafi, Petra Wolf, Helmut Krcmar. Process and Data-Oriented Approach for Bundling Corporate Reporting Duties to Public Authorities - A Case Study on the Example of Waste Management Reporting. 9th IFIP WG 8.5 International Conference on Electronic Government (EGOV), Aug 2010, Lausanne, Switzerland. pp.400-411, 10.1007/978-3-642-14799-9_34 . hal-01056571

\section{HAL Id: hal-01056571 \\ https://hal.inria.fr/hal-01056571}

Submitted on 20 Aug 2014

HAL is a multi-disciplinary open access archive for the deposit and dissemination of scientific research documents, whether they are published or not. The documents may come from teaching and research institutions in France or abroad, or from public or private research centers.
L'archive ouverte pluridisciplinaire HAL, est destinée au dépôt et à la diffusion de documents scientifiques de niveau recherche, publiés ou non, émanant des établissements d'enseignement et de recherche français ou étrangers, des laboratoires publics ou privés. 


\title{
Process and data-oriented approach for bundling corporate reporting duties to public authorities - A case study on the example of waste management reporting
}

\author{
Armin Sharafi ${ }^{1}$, Petra Wolf ${ }^{1}$, Helmut $\operatorname{Krcmar}^{1}$ \\ ${ }^{1}$ Technische Universität München, Chair for Information Systems I17, Boltzmannstr. 3, \\ 85748 Garching bei München, Germany \\ \{armin.sharafi, petra.wolf, krcmar\}@in.tum.de
}

\begin{abstract}
Recent bureaucracy cost surveys identify the issue of high financial burdens on government authorities and businesses. These burdens are often caused by a large number of regulations. Therefore, the purpose of process bundling is to redesign Business-to-government processes in a way that eliminates redundant contacts, but still fulfils all reporting duties. The application of our bundling approach shows benefits by replacing similar reporting duties. One possibility to do so is to reuse available data on the business side for numerous duties. This research illustrates an approach for identifying opportunities for data reuse and thus to reduction of bureaucracy costs. The case study applies this approach for environmental reporting duties. After surveying reporting duties in Germany, similar reporting duties with overlaps concerning their content and process were selected. Finally, opportunities for data reuse were derived and implemented.
\end{abstract}

Keywords: eGovernment, process bundling, data reuse, reporting duties, bureaucracy costs

\section{Introduction}

In the fall of 2008, the Federal Statistical Office in Germany identified 9.324 reporting duties between businesses and government in Germany. The expenses on the business side for complying with these duties are measured by using the Standard Cost Model (SCM) [1, 2]. The SCM "is designed to measure the administrative consequences for businesses. Today, it is the most widely employed method to do so" [2]. According to the SCM report, the German economy is charged with an annually amount of approximately 47.6 billion Euros, with 22.5 billion Euros due to national regulations and approximately 25 billion Euros based on EU- and international regulations [1]. As a result, businesses are dissatisfied with public administrations. They accuse their local as well as national government for being insufficiently transparent and following antiquated structures [3]. It is considered indispensable to counteract this appearance by reorganizing current administrative processes [4]. Lenk 
2 Process and data-oriented approach for bundling corporate reporting duties to public authorities - A case study on the example of waste management reporting

for example [5] states "without process reorganisation it is impossible for information technology to provide help, regarding quality improvement and more efficiency [...]" (translated from German into English). As a prerequisite for efficient eGovernment, process integration therefore attempts to achieve common process objectives like simplifying and speeding up administrative procedures, improving quality, enabling new tasks or the extension of opportunities for democratic participation [5]. In order to exploit potentials for modernization, it is necessary to examine underlying processes of Business-to-government (B2G) contacts like reporting duties [6]. Only focusing on organisation-wide processes can enable aspired customer orientation [7].

Since process reorganisation and process integration have already proved powerful approaches to improve efficiency in the industry domain, they are also applied to the public administration domain. The goal is to lower bureaucratic expenses, especially for businesses. Therefore, we analysed the area of environment reporting duties in order to identify B2G-process structures which might benefit from process. This led us to the following research question: What different types of reporting duties exist in the area of waste disposal management and how can they be bundled? At the same time, the underlying processes will not be modified in their nature. The intention of the process bundle construction can be summarized by contributing to the public welfare (lower bureaucracy costs), improving transparency and protecting the environment from unnecessary pollution.

The paper is structured as follows: Chapter two describes the approach for B2Gprocess analysis and process redesign. Afterwards, chapter three introduces the application domain environment by giving some facts about the waste disposal sector and illustrating three environmental reporting duties: the German electronic waste notification system (eANV), the electronic pollutant release-and transfer register $(E$ PRTR) and the environmental statistic report. We propose these processes for bundling. Chapter four illustrates the application of the approach in the investigated domain is described. The emphasis is on the content and the data flow between businesses and administration. At the end of this section we show, how the three processes can be bundled by reusing reporting data generated in one process. In section five and six, our findings are discussed and implications for further research are derived.

\section{Method and Approach}

We conducted a case study on environmental reporting duties of companies. This was done to identify groups of processes, which might be suitable for bundling. The aim is to provide a more efficient way of reporting a specific type of environment data to government. For being able to decide on "bundling candidates", it was essential to define how B2G processes should be integrated. Based on the assumption that there are many groups of similar reporting duties - referring to the data being reported criteria for bundling were chosen to measure similarity of reporting duties. This includes their structure and data content. 
Process and data-oriented approach for bundling corporate reporting duties to public authorities

- A case study on the example of waste management reporting 3

The applied approach adopts basic ideas and principles from well-established models used for business process management and reengineering within the industry sector [8] [9] [10]. Each approach aims at integrating processes and is mostly composed of four steps. Gaitanides [8] distinguishes between the steps process identification, process analysis, process design and process implementation. He describes the objectives of a goal-oriented management of the value-added chain (process bundle) regarding quality, time, costs and customer satisfaction. Geier [10] illustrates his procedure model by enumerating the steps determination of project objectives and content, analysis of the current situation, development of a target concept and implementation. Becker et al. [9] try to improve the existing process organisation constantly and incrementally through their concept of "Continuous Process Management". This concept is organized through a cyclic arrangement of its sub processes executing phase, analysis, goal-redefinition phase, modelling phase and business process reengineering phase [9]. To sum up, first the approaches aim at identifying relevant processes as input for further detailed analysis. The process analysis achieves a more detailed structuring of the main process by identifying subprocesses. The following step attains a target concept or design of a new process bundle. This is built up from the examined single processes by meeting the main reengineering goals like e.g. improvement of the chronological and logical order. The step implementation gives advice how to realize the desired construction [11].

Following the illustrated approaches, we identified basic structures of each model and designed an analysis approach. It is customized for its application to domains, which are characterized by a high number of reporting duties (e.g. environment). The approach is structured as follows (see Fig. 1) [12]:

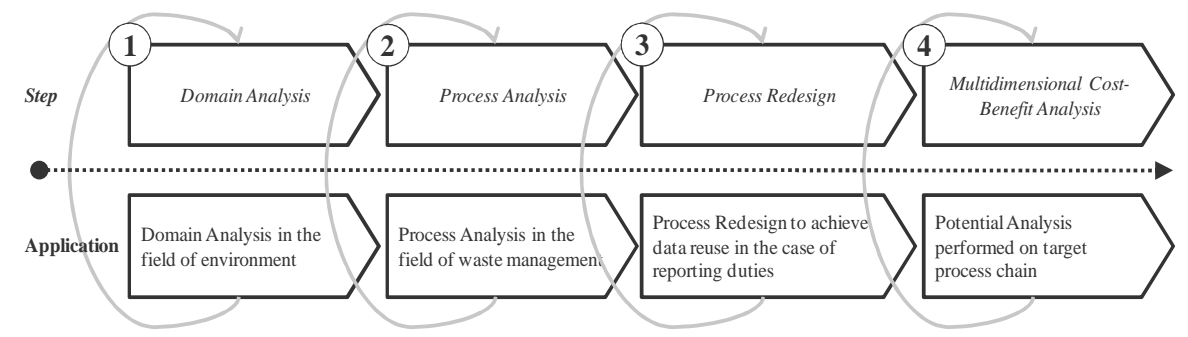

Fig. 1. Process model for process redesign for reporting data reuse

(Source: own illustration based on [12])

The derived approach consists of four successive steps. Firstly, it is necessary to define and to analyse the environment of the considered domain (Domain Analysis). Results are B2G processes, which might benefit from bundling. In the second step, selected processes have to be analysed in detail (Process Analysis). This is carried out to prove how they might be redesigned to achieve a more efficient state. Step three points out the issue to redesign processes in order to reuse reporting data (Process Redesign). In the final step, it is important to evaluate the potential benefit of the redesigned process (Multidimensional Cost-Benefit Analysis). Details of the individual steps are described in the course of the following case study. 
4 Process and data-oriented approach for bundling corporate reporting duties to public authorities - A case study on the example of waste management reporting

\section{Application Domain Environment}

\subsection{Industry Sector Waste Disposal}

This chapter gives some facts to get in touch with the domain waste disposal in Germany. Today, the waste disposal sector covers about 240.000 employees and a volume of about 50 billion Euro [13]. Since year 2000, the quantity of dangerous waste raised from 15 to 20 million tons a year. Therefore, 250.000 companies and 320 authorities create and deal with round about 10.000 records of proper waste management, 3 million data sheets and 14 million dock receipts concerning the waste notification system [13]. According to the Federal Statistical Office, 214 reporting duties were identified, including the identified processes in the Domain Analysis, concerning the industrial sector "wastewater, waste and miscellaneous waste disposal" [14]. Through a detailed consideration of each duty regarding corresponding bureaucracy, it is possible to allocate specific costs to 177 reporting duties. Summed up, these processes cause bureaucracy costs of 176,947 million Euro [14]. This amount demonstrates the relevance to measure cost reduction. After a brief explanation of 3 processes analysed in our case study, the Process Analysis explores the listed processes in more detail. The goal is to identify concrete links as possibilities to combine them to integrated process bundles [12].

\subsection{German Electronic Notification System (eANV)}

All involved actors (producer and transporter of waste, waste disposal contractor, authority) have to fill out the "waste data sheet". Besides data about type and quantity of waste, it also contains further data about participating waste disposal partners and the actual transaction [15]. This includes the collection, transport and disposal of waste with an obligation to keep records for the disposal of dangerous waste [16]. So, every involved actor has to keep certain regulations which dictate to create, complete or store corresponding waste data sheets [15]. According to this, many procedures seem to appear regularly with almost the same task. The content of the forms is quite similar, although there are different formats (paper based forms etc.), levels of detail and partially different addressees. The electronic waste notification system (eANV) will soon be introduced in Germany (legislative basis $\S 45 \mathrm{Abs}$. $2 \mathrm{KrW}-/ \mathrm{AbfG}$ ). The currently non-automated procedure of the waste notification system often causes redundancies, inconsistencies concerning the data collection and as a result avoidable administrative costs. In order to reduce the appearing paper logistics, eANV aims at substituting paper forms through an electronic way of data registration. The technical infrastructure for running eANV is provided through a central platform. It enables a uniform nationwide data exchange between all involved actors [16]. This will contribute to improvements of the organisation of the nationwide waste disposal and to reduce data exchange efforts [17]. 
Process and data-oriented approach for bundling corporate reporting duties to public authorities

- A case study on the example of waste management reporting 5

\subsection{E-PRTR}

The aim of the introduction of the European Pollutant Release and Transfer Register (E-PRTR) is to contribute to transparency and public participation in environmental decision-making [18]. The E-PRTR contains important environmental data from industrial facilities within the EU. It replaces and improves upon the previous European Pollutant Emission Register (EPER). The new register contains data, annually reported by some 24.000 industrial facilities covering 65 economic activities across Europe, including several industry sectors like waste and waste water management [18]. Each facility which fulfils certain criteria (e.g. exceedance of determined threshold values) has to report to E-PRTR including data about the amounts of pollutant releases to air, water and land as well as off-site transfers of waste and of pollutants in waste water from a list of 91 key pollutants. Data are mostly reported annually by the respective facility to responsible authorities [18]. The technical support is a nationally data acquisition software (BUBE), which is used by the operator to transfer reportable data online to PRTR, followed by automated transmission [19]. This reporting duty is important for our considerations, because waste producers and waste disposal contractors have to notify type and amount of waste.

\subsection{Environmental Statistic Report Waste Disposal}

According to the German environmental law (UStatG) $\S 1$, statistics have to be raised for purposes of environmental policies and fulfilling European and international reporting duties. UStatG $\S 2$ demands for statistics which include inquiries about waste disposal, waste which has to be proved for disposal, disposal of certain waste (UStatG $\S 5$ ), etc. Especially concerning the waste disposal, $\S 3$ paragraph 1 registers data from involved facilities requiring admissions for disposing waste. That is why for example type, amount, nature and origin of the handled waste have to be reported every year. Number, type and location of the facility have to be reported every two years to the responsible authority. The same companies (waste producers and waste disposal contractors) are obliged to report. This is just a small excerpt of the UStatG to display the content of the considered law and its resulting reporting duties [12]. In order to enable electronic processing of reporting duties, the need for an online-available reporting system arised. Therefore, the eSTATISTIC.core system was built up in 2005, developed by national statistical agencies. It provides the possibility for companies and authorities to report automatically data online [20].

\section{Application of the Analysis Approach}

The following sections describe the four phases of the approach in detail as well as its application in our use case. 
6 Process and data-oriented approach for bundling corporate reporting duties to public authorities - A case study on the example of waste management reporting

\subsection{Domain Analysis}

The development of the Domain Analysis was inspired by the Needs Driven Approach (NDA) [21]. NDA aims at analysing and representing collaboration, for example by identifying involved actors, interactions, tasks or examining legislative frameworks, work processes, used tools or data storages [21]. In this case, the NDA is used to collect B2G contacts in the domain environment. This is required to identify similar reporting duties as a basis for bundling. The Domain Analysis is important, because following steps are based on its results [22]. In order to identify domain knowledge within the Domain Analysis, a feasibility study [12] developed an approach to identify and collect reporting duties and B2G processes. This includes the completion of four steps called task analysis, (high-level) work process analysis, interaction analysis and selection of candidates for the process analysis [12].

First of all, the task analysis delimits the field of investigation and identifies reporting duties. Therefore, we studied legislative specifications concerning information and licensing requirements related to environmental protection or environmental authorities. To gain necessary domain knowledge, we used sources like process descriptions (e.g. eGovernment sites), legal documents (e.g. reporting forms) and regulations (e.g. government service catalogues), organisational and task plans, workflow diagrams, descriptions of the IT architecture as well as reports concerning the fulfilment of the designated reporting duties. The result is a list of $\mathrm{B} 2 \mathrm{G}$ processes.

In the course of the work process analysis, we categorized identified B2G processes according to their structure or process type (reports, applications, data requests). Further, they were classified referring to their content - i.e. type of substance being reported on (e.g. waste, waste water) and object of reporting (e.g. quantity, pollutants) - on the basis of a domain model for environment compliance [23]. Finally, we ended up with a systematized composition of the investigated processes.

Thirdly, the interaction analysis aims at identifying all actors involved in a B2G contact. It is based on the analysis of documents, especially legislative specifications and forms used in the domain environment.

Step four, the selection of candidates for the Process Analysis, uses previous results to select suitable bundling candidates for the design of efficient eGovernment processes. All processes are filtered according to certain attributes (similarity of actors and structure), until a set of processes remains [25].

At the beginning of the research, relevant data about the regarded domain were collected. Relevant in this case are e.g. involved actors on the business side, involved authorities, data to be supplied by the business side, type and frequency of reporting duty, medium, interface and information system for data transfer, legal basis and bureaucracy costs of analysed B2G reporting duties. The collection of relevant data is often difficult, because sub-processes are mostly supported by different IT-systems with different actors and institutions involved in the process. Additionally, most information sources are not digital. That's why problems concerning format inconsistencies occur [9]. 
Process and data-oriented approach for bundling corporate reporting duties to public authorities - A case study on the example of waste management reporting

According to the analysis phase of the "Continuous Process Management" process [9], collection of required information includes three steps: Firstly, data sources for domain information need to be identified, accompanied by the provision of a corresponding access to the implied information. Secondly, gathered data has to be prepared for its syntactical suitability, for example, to obtain a common data format (e.g. XML). The last step proves the semantic correctness of the collected information. This is done to get an information base, which is suitable for following process evaluation [9]. As a result, the analysis in the field of environment identified 339 processes between business and administration [24]. The structured collection of these processes in a process data library allowed us to select processes for bundling by means of specific criteria (e.g. common laws, involved actors) [25]. Fig. 2 represents a part of the library.

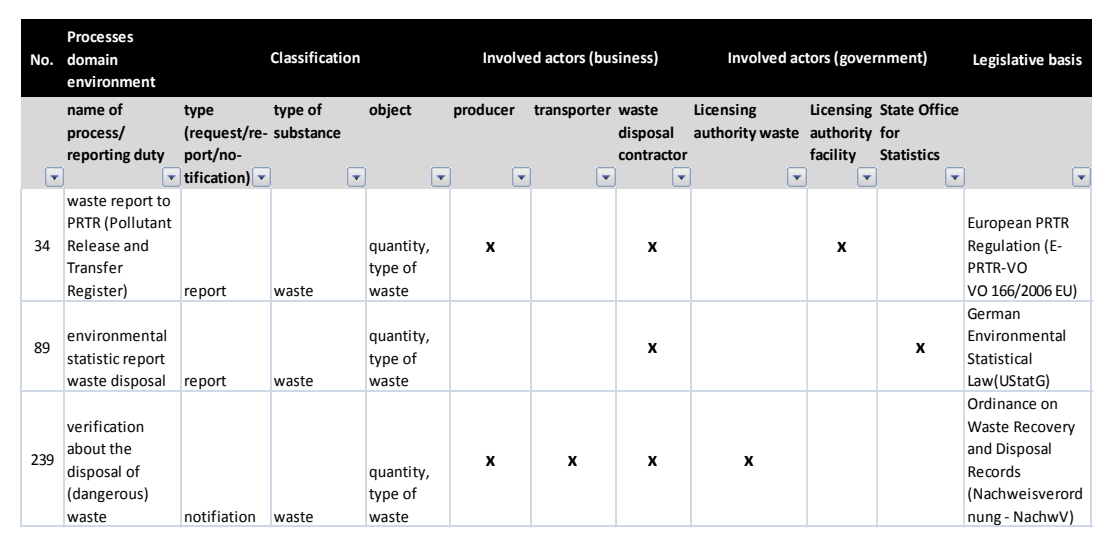

Fig. 2. Process data library - part of the resulting list through the Domain Analysis

(Source: own illustration according to [12])

By using these criteria, it was possible to form groups with content-related similarities. Those similarities can occur e.g. in form of concerned type of substance, involved actors or corresponding reporting period etc. The largest group - referring to the type of substance to be reported on - turned out to be reporting duties concerning the waste disposal management sector. Three of them deal with type and quantity of waste and are therefore similar in their content. All characteristics mentioned before help to determine a pre-selection of processes. Analogies regarding the classification through certain criteria, like type of substance or regulations by law as well as the consideration of the results of a document analysis, result in a small variety of adequate process bundling candidates. This includes $e A N V, E-P R T R$ as well as environmental statistic report.

\subsection{Process Analysis}

The Process Analysis investigates selected processes. The purpose is to reveal possibilities for their integration towards desired process bundles. This step is also 
8 Process and data-oriented approach for bundling corporate reporting duties to public authorities - A case study on the example of waste management reporting

based on principles of the NDA, e. g. by performing (detailed) work processes and tools employed [21]. In addition, the Process Analysis uses the concept of standardized data profiles to enable a structured procedure. This allows an examination of regarded processes according to predefined characteristics.

The (detailed) work process analysis aims at identifying starting points and requirements for the integration towards process bundles through a detailed functional description. Techniques used for that purposes are interviews and business process analysis with a functional as-is profile. At the same time, the process costs are analysed according to the SCM model. Besides this, the degree of routine (number of possible appearances) and the complexity concerning the number of possible variants or length of the process will be recorded.

The analysis of the used tools identifies the current IT support including the analysis of interfaces for data exchange as well as transport protocols and data formats. Information required for the Process Analysis comes from legal regulations, public documents, product and system descriptions, interfaces specifications and interviews [12]. Detailed descriptions of processes form the starting point for the following construction of process bundles. Identified processes are analysed regarding their organisational, technical and legal characteristics to derive bundling requirements. The outcome of the Process Analysis consists of three current state profiles. Their investigation (concerning possibilities for connecting them by comparing attributes) ends in a target state profile. The functional conception explores factual requirements, whereas the technical conception examines relevant criteria out of the field information and communication technology [12].

\subsection{Process Redesign for reporting data reuse}

The proposed procedure of redesigning is inspired by the well-established "Structured Analysis" by DeMarco [26] which contains methods for an analysis of systems. Comparable approaches exist by Ross and Schomann [27] or Mac Menamin [28]. Following their guidelines, the current state of a system has to be raised through an analysis of existing processes and systems first. Secondly, necessary changes have to be defined to develop the desired model [26]. The goal is to replace the redundancy of reporting duties through the reuse of available data. According to [29], process bundling is concerned with changing or redirecting flow of data between activities without changing the actual content of the data.

Every facility producing or dealing with dangerous industrial waste has to report data according to the $e A N V, P R T R$ and environmental statistic report waste disposal to the responsible authority (see Fig. 3). The linkage between environmental statistic report waste disposal and eANV takes place through aggregation of reportable data, involved actors which occur in form of the waste disposal contractor and content of the reportable data. The combination of PRTR and the statistic report waste disposal can also be implemented through aggregation of reportable data, involved actors in form of waste producer and waste disposal contractor and content of the report. From the functional point of view, the realization of the process redesign intends to automatically accumulate data. 
Process and data-oriented approach for bundling corporate reporting duties to public authorities - A case study on the example of waste management reporting

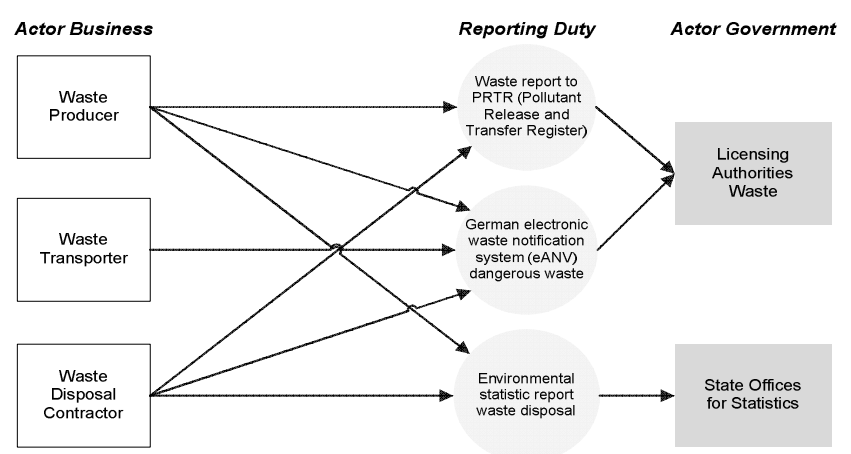

Fig. 3. Three reporting duties of companies (Source: own illustration)

Fig. 4 illustrates the data flow between eANV, PRTR and statistical reports as well as the integrated data flow between all involved actors. This BPMN process model shows the combined and integrated overall process. The data of the verification conducted on hazardous waste (eANV) report is used to generate the PRTR report of the producer and the waste disposal contractor. The eANV data are also used for the preparation of statistical reports of both actors. All reports will then be sent in a further step to the appropriate authority. The goal of the design of the technical implementation is to provide as much support as possible for the economy to fulfil reporting tasks demanded by government.

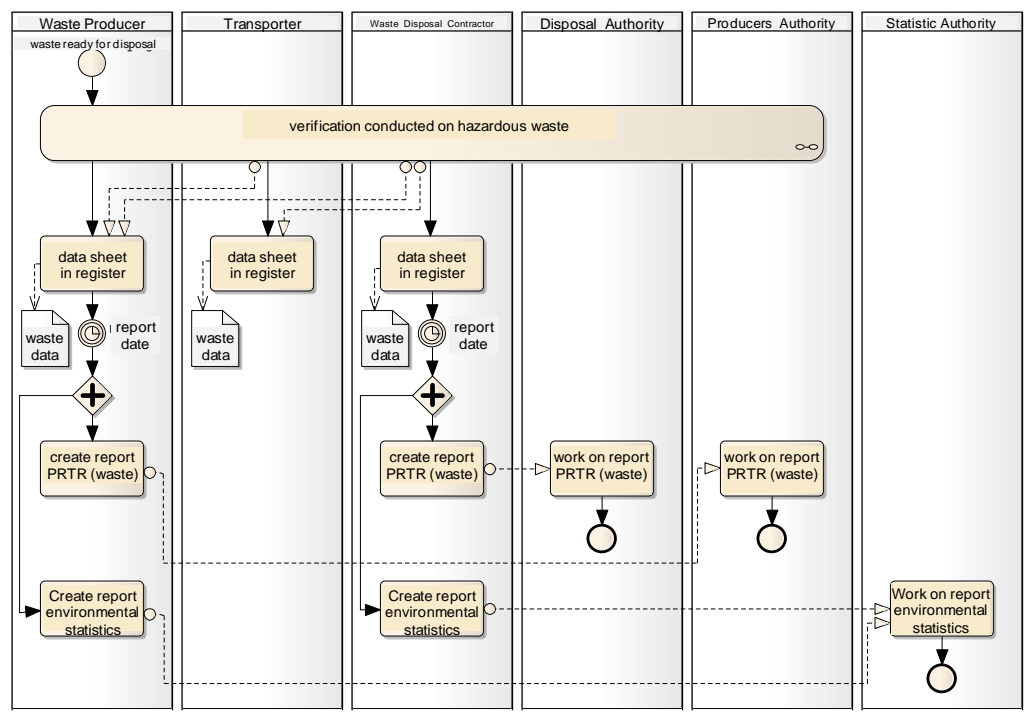

Fig. 4. Target process bundle PRTR - eANV - environmental statistic report (Source: own illustration according to [12]) 
10 Process and data-oriented approach for bundling corporate reporting duties to public authorities - A case study on the example of waste management reporting

Finally, the benefit of bundling is analysed by the use of the Multidimensional Cost-Benefit Analysis. The objectives of the procedure are summarized as reduction of the administrative expense for businesses as well as improvement of data quality. The process bundling simplifies the procedure of reporting data to responsible authorities. Actually, different reporting duties with similar content are often processed in different divisions of a company. This separate processing of data leads to unsatisfactory results in the form of inconsistent reports and resulting contradictions. Through reuse of data, reliability of reported data will be improved and fault rates reduced. Although SCM is not able to give evidence about the detailed saving potential, according to estimations of experts, the proposed approach will pay off. Therefore, it is qualified to reduce bureaucracy costs. But a point of criticism concerning the SCM is that it is not a method to calculate actual administrative costs, but rather delivers estimates, using mean values. So, highly efficient or inefficient procedures will not be taken into account. As a result, the appliance of the SCM can provide distorted results [30]. To obtain actual data, it is necessary to perform benchmarks including all companies [31]. Furthermore, there is no statement expressed about the benefit but about costs [32].

\section{Conclusion}

Companies suffer from high bureaucracy costs incurred by reporting duties to authorities. This paper describes the application of an approach for process bundling, in order to reduce efforts for businesses. The main target in this case was to bundle several individual processes by reusing reporting data. The application of the approach is illustrated in form of a case study. It is based on and developed by the consideration of common principles of process management and reengineering. The appliance in the selected domain demonstrates a way to reduce bureaucracy costs, as well as to achieve common eGovernment objectives. Individual processes were integrated, which provides advantages such as reduced costs, transparency and higher efficiency. The appliance of the approach in this case was possible because of many overlaps between reporting duties. First, we conducted a Domain Analysis to identify reporting duties in the domain and to filter relevant and similar ones for bundling. The next step (Process Analysis) explored selected processes in detail according to defined characteristics. Then, suitable reporting duties are redesigned with the goal to replace redundancies of reporting duties through the multiple use of available data (Process Bundle Determination). Finally, we evaluated the benefit of the reporting duty bundle to derive the potential of the combined process. The use of the approach also showed the necessity for iterative customizations to meet the requirements of the domain. We identified three reporting duties dealing with data about waste and consolidated them into one integrated process. This illustrates potential to contribute to the reduction of bureaucracy costs. 
Process and data-oriented approach for bundling corporate reporting duties to public authorities - A case study on the example of waste management reporting

\section{Outlook}

Despite of some restrictive factors (application of the approach in only one domain), the model represents its potential by the combination of several suitable processes in order to reduce bureaucracy costs. This is getting more and more important to consolidate public finance and to improve the capacity to act through more flexibility [4]. Since the approach has been applied in the domain environment, the applicability in other areas is not verified yet. This is necessary to draw conclusions about the generalization of the approach. The applicability of the model has to be examined in terms of e.g. simplicity and quality. For that matter it is required to consider which criteria may be used for a bundling of processes. Likewise, it is important to elicit which procedure is applicable to derive process criteria and their relationships for the regarded domain. Furthermore, feasibility of integrated processes as a result of the approach has to be examined. This also applies to potential savings indicated in this paper. Last but not least, it is sensible to review the completeness of the approach. Therefore further research is planned to implement a bundle of reporting duties between business and administration.

Acknowledgments. We would like to thank the German Federal Ministry of the Interior for their support and funding of the research project.

\section{References}

1. Statistisches Bundesamt Deutschland, $\mathrm{Zu}$ viel Bürokratie?, http://www.destatis.de/jetspeed/portal/cms/Sites/destatis/Internet/DE/Content/Publikationen/ STATmagazin/Sonstiges/2009_08/PDF2009_08,property=file.pdf; [cited 15.02.2010].

2. O.A., Standard Cost Model Manual, http://www.oecd.org/dataoecd/32/54/34227698.pdf; [cited 18.02.2010].

3. Rodenhagen, J., Diekhans, B., Rieckmann, P.: Prozessmanagement im Kontext des EGovernment 2.0 - Einsatzfelder, Rahmenbedingungen, und aktuelle Maßnahmen. Praxis der Wirtschaftsinformatik 265 (2009) p.36-50

4. Bundesministerium des Innern, E-Government 2.0 - Das Programm des Bundes, http://www.cio.bund.de/cae/servlet/contentblob/63262/publicationFile/4016/egov2_program m_des_bundes_download.pdf; [cited 11.02.2010].

5. Lenk, K.: Notwendige Revisionen des Geschäftsprozessdenkens. In: Wimmer, M. (ed.): Impulse für eGoovernment: Internationale Entwicklungen, Organisation, Recht, Technik, Best Practices. Österreichische Computer Gesellschaft, Wien (2002) p.61-71

6. Becker, J., Algermissen, L., Niehaves, B.: Vorgehensmodell zur Selektion von eGovernment-Prozessen. eGovernment-Präsenz Fachzeitschrift des Kompetenzzentrums Uni Münster 4 (2004)

7. Beyer, L.: Reengineering. In: Blanke, B., Bandemer, S., Nullmeier, F., Wewer, G. (eds.): Handbuch zur Verwaltungsreform. Opladen (2001) p.118-126

8. Gaitanides, M.: Prozessorganisation - Entwicklung, Ansätze und Programme des Managements von Geschäftsprozessen. Verlag Franz Vahlen, München (2007)

9. Becker, J., Kugeler, M., Rosemann, M.: Prozessmanagement. Springer, Berlin Heidelberg (2008) 
12 Process and data-oriented approach for bundling corporate reporting duties to public authorities - A case study on the example of waste management reporting

10.Geier, C.: Optimierung der Informationstechnologie bei BPR-Projekten. Deutscher Universitäts-Verlag, Wiesbaden (1999)

11.Schulze, G.: Bürokratie- und Regulierungskosten in der chemischen Industrie - Potenziale zu ihrer Reduktion. Verband der chemischen Industrie, Frankfurt am Main (2009)

12.Wolf, P., Sharafi, A., Krcmar, H., Guenther, H., Komm, M., Ortmann, E., Schäfer, M.: Machbarkeitsstudie Prozessketten Umwelt. Lehrstuhl für Wirtschaftsinformatik, TU München, Siemens IT Solutions and Services, Berlin (2009)

13.Viola, G.: Behörden und Unternehmen entlasten - Bürokratiekosten senken, http://www.egovernment-

computing.de/index.cfm?pid=7476\&pk=202981\&print=true \&printtype=article; $\quad$ [cited 11.02.2010].

14.Statistisches Bundesamt, WebSKM, https://www-skm.destatis.de/webskm/online; [cited 12.02.2010].

15.Landesamt für Natur Umwelt- und Verbraucherschutz Nordrhein-Westfalen, http://www.lanuv.nrw.de/abfall/abfstroeme/einzelentsor.htm; [cited 12.02.2010].

16.Zentale Koordinierungsstelle der Länder, www.zks-abfall.de; [cited 15.02.2010].

17.Abfallüberwachungssystem ASYS, http://www.asysnet.de/; [cited 09.02.2010].

18.PRTR: Schadstofffreisertzungs- und Verbringungsregister, www.prtr.bund.de; [cited 11.02.2010].

19.BUBE-Online, http://home.prtr.de/index.php?pos=el_prtr/bube/; [cited 09.02.2010].

20.eSTATISTIK.core, http://www.statspez.de/core/; [cited 10.02.2010].

21.Schwabe, G., Krcmar, H.: Piloting Socio-Technical Innovation. European Conference on Information Systems, Wien (2000)

22.Krallmann, H., Schönherr, M., Trier, M.: Systemanalyse im Unternehmen. Oldenbourg Verlag, München (2007)

23.Krcmar, H., Dold, G., Fischer, H., Strobel, M., Seifert, E.: Informationssysteme für das Umweltmanagement - Das Referenzmodell ECO-Integral, München, Wien (2000)

24.Bundesregierung: Informationspflichten der Wirtschaft, http://www.bundesregierung.de/Content/DE/StatischeSeiten/Breg/Buerokratieabbau/zahlenund-fakten-zum-buerokratieabbau.html; [cited 08.02.2010].

25.Wolf, P., Jurisch, M., Krcmar, H.: Analyse und Design von Prozessketten. Fachtagung Verwaltungsinformatik (FTVI), Koblenz (2010)

26.DeMarco, T.: Structured Analysis and System Specification. Yourdon Press, New York (1978)

27.Ross, D., Schoman Jr, K.: Structured analysis for requirements definition. IEEE Transactions on Software Engineering (1977)

28.MacMenamin, S., Palmer, J.: Strukturierte Systemanalyse. Hanser (1988)

29.Jurisch, M., Wolf, P., Krcmar, H.: Toward a formal approach to process bunding in public administrations. EGOV 2010. Springer Verlag Berlin et al (2010)

30.den Butter, F., de Graaf, M., Nijsen, A.: The Transaction Costs Perspective on Costs And Benefits of Government Regulation. Tinbergen Institute Discussion Papers (2009)

31.Staatssekretariat für Wirtschaft SECO: Messung der Bürokratiekosten der Mehrwertsteuer Gesetzgebung auf Basis des Standard-Kosten-Modells, http://www.seco.admin.ch/themen/00374/00459/02118/index.html?lang=de\&download=NH zLpZeg7t,lnp6I0NTU04212Z61n1acy4Zn4Z2qZpnO2Yuq2Z6gpJCEfHx9fGym162epYbg2c _JjKbNoKSn6A; [cited 19.02.2010].

32.Slodowicz, J., Zenhäusern, P., Vaterlaus, S.: Verwendungsmöglichkeiten des StandardKosten-Modells - Eine Analyse des schweizerischen Kontexts. Plaut Economics, Olten (2007) 